\title{
GAMBARAN KELENGKAPAN RESEP SECARA ADMINISTRATIF DAN FARMASETIK DI APOTEK K24 POS PENGUMBEN
}

\author{
Nurwulan Adi Ismaya, Ita La Tho, Muhammad Iqbal Fathoni \\ Sekolah Tinggi Ilmu Kesehatan Kharisma Persada \\ Tangerang Selatan, 15417, Indonesia \\ E-mail: nurwulan@masda.ac.id
}

\begin{abstract}
ABSTRAK
Dalam alur pelayanan resep, apoteker wajib melakukan skrining resep yang meliputi skrining administratif, kesesuaian farmasetik dan pertimbangan klinis. Aspek administratif dan farmasetik resep dipilih karena merupakan skrining awal pada saat resep dilayani di apotek karena mencakup seluruh informasi di dalam resep yang berkaitan dengan kejelasan tulisan obat, keabsahan resep, dan kejelasan informasi di dalam resep. Penelitian ini di lakukan untuk mengetahui bagaimana kelengkapan administratif dan farmasetik resep di Apotek K-24 Pos Pengumben periode bulan agustus sampai desember tahun 2018 memenuhi ketentuan kelengkapan resep menurut Permenkes No.73 Tahun 2016. Dilakukan pengecekan administratif dan farmasetik terhadap 288 lembar resep dengan mengisi tabel pengambilan data (Checklist) sesuai dengan aspek kelengkapan yang ditinjau. Dari hasil penelitian menunjukan kejadian ketidaklengkapan resep di Apotek K-24 Pos Pengumben yaitu berat badan 99\%, jenis kelamin sebanyak 36\%, usia pasien sebanyak $28 \%$, nama pasien $1 \%$, nama dokter sebanyak $6 \%$, SIP sebanyak $28 \%$, alamat sebanyak $1 \%$, nomor telfon sebanyak $15 \%$, paraf sebanyak 53\%, tanggal resep sebanyak 2\%, sediaan sebanyak 25\%, kekuatan sediaan sebanyak 24\%, stabilitas obat 1\%, dan kompatibilitas 0\%. Kelengkapan resep di Apotek K-24 Pos Pengumben belum memenuhi ketentuan kelengkapan administratif dan farmasetik sesuai dengan Permenkes No.73 Tahun 2016.
\end{abstract}

Kata Kunci : Kelengkapan Administratif, Kelengkapan Farmasetik

\begin{abstract}
In the prescription service flow, pharmacists are required to do prescription screening which includes administrative screening, pharmaceutical suitability and clinical considerations. The administrative and pharmacetic aspects of the prescription were chosen because it was the initial screening when the recipe was served at the pharmacy because it included all the information in the recipe relating to the clarity of the drug writing, the validity of the recipe, and the clarity of the information in the recipe. This research was conducted to find out how the administrative and pharmacetic prescriptions at the Kumbum Pos Pengumben Pharmacy in the period of August to December 2018 fulfilled the prescription completeness according to Minister of Health Regulation No. 73 of 2016. Administrative and pharmacy checks were carried out on 288 prescription sheets by filling in the tables Data collection (Checklist) in accordance with the completeness aspects reviewed. From the results of the study showed the incidence of incomplete prescriptions at the PostPengumben K-24 Pharmacy namely 99\% body weight, 36\% sex, 28\% patient age, 1\% patient name, 6\% doctor name, 28\% SIP, as many as 1\%, telephone number as much as 15\%, initial as much as 53\%, prescription date as much as $2 \%$, preparation as much as $25 \%$, dosage strength $24 \%$, drug stability $1 \%$, and 0\% compatibility. The complete prescription at the K-24 Pharmacy Station Post has not fulfilled the administrative and pharmaceutical requirements in accordance with Permenkes No. 73 of 2016.
\end{abstract}

Keywords

: administrative requirements, pharmaceutical requirements 


\section{PENDAHULUAN}

Katzung 2009 dalam Sandy (2010), resep yang baik harus memuat cukup informasi yang memungkinkan ahli farmasi yang bersangkutan mengerti obat apa yang akan diberikan kepada pasien. Namun pada kenyataannya, masih banyak permasalahan yang ditemui dalam peresepan. Beberapa contoh permasalahan dalam peresepan adalah kurang lengkapnya informasi pasien, penulisan resep yang tidak jelas atau tidak terbaca, kesalahan penulisan dosis, tidak dicantumkannya aturan pemakaian obat, tidak menuliskan rute pemberian obat, dan tidak mencantumkan tanda tangan atau paraf penulis resep (Wihartini, 2009).

Permasalahan dalam peresepan merupakan salah satu kejadian medication error. Bentuk medication error yang terjadi adalah pada fase prescribing (error terjadi pada penulisan resep) yaitu kesalahan yang terjadi selama proses peresepan obat atau penulisan resep. Dampak dari kesalahan tersebut sangat beragam, mulai yang tidak memberi resiko sama sekali hingga terjadinya kecacatan bahkan kematian (Hartayu dan Aris, 2010).

Hasil penelitian dari Prawitasari (2009) menemukan bahwa dalam peresepan ditemukan ketidakjelasan penulisan aturan pakai sebanyak 50,8\%, kesalahan penulisan dosis obat sebanyak
$50,8 \%$ dan paraf dokter sebanyak 6,8\%. Selain itu, penelitian oleh Octavia (2011) mendapatkan kesalahan penulisan bentuk sediaan sebanyak $60,2 \%$, rute pemberian $84,2 \%$ dan frekuensi penggunaan obat $75,5 \%$. Beberapa contoh permasalahan dalam peresepan adalah kurang lengkapnya informasi pasien, penulisan yang tidak jelas atau tidak terbaca, kesalahan penulisan dosis, tidak dicantumkannya aturan pemakaian obat, tidak menuliskan rute pemberian obat, dan tidak mencantumkan tanda tangan atau paraf penulis resep (Wihartini, 2009). Banyak faktor yang mempengaruhi permasalahan dalam peresepan, sehingga diperlukan kepatuhan dokter dalam melaksanakan aturan-aturan dalam penulisan resep sesuai undang-undang yang berlaku (Sandy, 2010).

Tindakan nyata yang dapat dilakukan untuk mencegah medication error oleh seorang farmasis adalah melakukan skrining resep atau pengkajian resep. Pengkajian resep dilakukan dengan tujuan untuk mencegah terjadinya kelalaian pencantuman informasi, penulisan resep yang buruk dan penulisan resep yang tidak tepat. Apoteker harus memahami dan menyadari kemungkinan terjadinya kesalahan pengobatan dalam proses pelayanan. Hal ini dapat dihindari apabila apoteker dalam menjalankan 
prakteknya sesuai dengan standar yang telah ditetapkan.

Apotek k24 Pos Pengumben adalah apotek yang baru berdiri pada tahun 2015 dan merupakan apotek franchise dari PT.KA DUA EMPAT yang berlokasi di Jl.Pos Pengumben Raya No35C. Terhitung dari awal dibuka hingga sekarang Apotek k-24 Pos Pengumben sudah 4 tahun berdiri. Letaknya yang cukup dekat dengan rumah sakit dan beberapa praktek dokter membuat membuat Apotek ini memiliki jumlah peresepan yang cukup banyak dan untuk peresepan tiap harinya ini mencapai 10-20 resep dengan jumlah petugas yang berjaga 2 orang setiap Shift. Sebagai apotek yang masih baru dibuka, maka masih belum ada suatu peneliti yang melakukan penelitian tentang gambaran kelengkapan resep secara administratif dan farmasetik. Peneliti juga adalah salah satu karyawan di Apotek k-24 Pos Pengumben maka untuk memudahkan melakukan penelitian dan pengambilan data maka peneliti menentukan Apotek ini yang menjadi tempat Penelitian. Masih banyaknya resep yang belum lengkap secara administratif dan secara farmasetik membuat peneliti tertarik untuk melakukan penelitian lebih lanjut tentang Gambaran Kelengkapan Resep Secara
Administratif dan Farmasetik di Apotek k24 Pos Pengumben.

\section{METODE}

Jenis penelitian yang digunakan adalah penelitian deskriptif dengan rancangan Cross Sectional. Cross Sectional adalah suatu penelitian untuk mempelajari dinamika korelasi antara faktor-faktor dengan efek dengan cara pendekatan observasi atau pengumpulan data sekaligus pada suatu saat (Notoatmodjo,2010). Pengumpulan data dilakukan dengan cara retrospektif, yaitu suatu jenis penelitian yang didasarkan pada data resep masuk dengan maksud untuk mengetahui kelengkapan persyaratan administratif dan farmasetik dari resep yang diterima oleh Apotek K24 Pos Pengumben selama Bulan Agustus sampai Desember tahun 2018.

Pengumpulan data melalui studi dokumenter dari data resep yang diterima dengan metode observasi dan lembar check list. Hal ini di maksudkan untuk mengetahui usia pasien, jenis kelamin pasien, berat badan pasien, nama dokter, SIP, alamat, nomor telfon, paraf dokter, tanggal resep, bentuk sediaan, kekuatan sediaan, stabilitas obat dan kompabilitas pada resep yang diperoleh di Apotek K24 Pos Pengumben.

Populasi adalah keseluruhan subjek yang akan diteliti. Data yang 
diambil adalah seluruh resep yang diterima selama periode Bulan Agustus sampai Desember tahun 2018 di Apotek K24 Pos Pengumben dengan jumlah 1030 resep (Sumber :Data Arsip Apotek K24 Pos Pengumben).

Sampel merupakan bagian dari jumlah dan karakteristik yang dimiliki oleh populasi (Notoadmodjo,2010). Sampel pada penelitian ini adalah Resep Apotek K24 Pos Pengumben Bulan Agustus sampai Desember 2018. Besaran sampel dalam penelitian ini ditentukan berdasarkan rumus Slovin menurut Sugiyono (2011:87). Adapun penelitian ini menggunakan rumus Slovin karena dalam penarikan sampel, jumlahnya harus representative agar hasil penelitian dapat digeneralisasikan dan perhitungannya pun tidak memerlukan table jumlah sampel, namun dapat dilakukan dengan rumus dan perhitungan sederhana. Rumus Slovin untuk menentukan sampel adalah sebagai berikut :

$$
n=\frac{N}{1+N(e)^{2}}
$$

Keterangan :

$\mathrm{n}$ = banyaknya sampel

$\mathrm{N}=$ ukuran populasi

$\mathrm{e}=$ derajat kepercayaan $5 \%(0,05)$

dimana dilakukan perhitungan sebagai berikut :

$$
\begin{gathered}
n=\frac{1030}{1+(1030 \times 0.0025)}=\frac{1030}{3.575} \\
=288 \text { resep }
\end{gathered}
$$

Pengambilan jumlah sampel dengan mengikuti teknik sampling. Teknik sampling adalah teknik pengambilan suatu sampel (Sugiyono, 2010:56). Adapun teknik pengambilan sampel, dengan menggunakan teknik sampel acak sistematis (systematic random sampling). Alasan menggunakan teknik ini karena yang menjadi populasi dalam penelitian ini dianggap homogen karena sampel yang diambil adalah jumlah resep yang masuk ke Apotek K24 Pos Pengumben pada Bulan Agustus sampai Desember 2018. Prosedur pengambilan sampel adalah dengan interval tertentu yaitu dengan perhitungan berikut ini :

$$
k=\frac{N}{n}=\frac{1030}{288}=3.5 \sim 3
$$

Keterangan :

$$
\begin{aligned}
& \mathrm{k}=\text { interval } \\
& \mathrm{N}=\text { ukuran populasi } \\
& \mathrm{n}=\text { banyaknya sampel }
\end{aligned}
$$

Alasan menggunakan interval adalah bagi peneliti cukup sederhana dan memungkinkan ketidakadilan dapat dihindari. Pengumpulan data menggunakan teknik observasi dan check list dengan cara retrospektif yang menelusuri resep pasien selama Bulan 
Agustus sampai Desember 2018 di Apotek K24 Pos Pengumben.

\section{HASIL}

Pada penelitian ini, ada sebanyak 1080 resep pada bulan agustus sampai dengan desember tahun 2018 masuk ke apotek k-24 pos pengumben. Berdasarkan perhitungan dengan menggunakan rumus slovin maka populasi yang menjadi sampel adalah sebanyak 288 lembar resep. Resep tersebut diamati kelengkapan resep yang mencakup; kelengkapan secara administratif yaitu data terkait pasien (nama pasien, usia pasien, jenis kelamin pasien, berat badan pasien), data terkait dokter (nama dokter, SIP, alamat, nomor telfon, paraf dokter), tanggal penulisan resep, kelengkapan secara farmasetik yaitu bentuk sediaan, kekuatan, stabilitas obat dan kompatibilitas obat.

\section{Penelitian tentang kelengkapan} resep ini dilakukan terhadap 288 lembar resep yang masuk ke apotek k-24 pos pengumben selama periode bulan agustus sampai desember tahun 2018, dengan mengamati kelengkapan resep secara administratif dan farmasetik. Dalam pengkajian resep ini digunakan parameter berupa pedoman penulisan resep yaitu Peraturan Menteri Kesehatan No. 73 Tahun 2016 tentang standar pelayanan kefarmasian di Apotek. Melalui hasil pengamatan dari 288 lembar resep, diketahui masih banyak terdapat ketidaklengkapan dalam penulisan resep.

Tabel 1. Kelengkapan data terkait pasien resep secara administratif

\begin{tabular}{ccccc}
\hline Data Terkait Pasien & \multicolumn{2}{c}{ Ada } & \multicolumn{2}{c}{ Tidak Ada } \\
\cline { 2 - 5 } & $\mathbf{f}$ & $\mathbf{\%}$ & $\mathbf{f}$ & $\mathbf{\%}$ \\
\hline Nama Pasien & 285 & 99 & 3 & 1 \\
\hline Usia Pasien & 206 & 72 & 82 & 28 \\
\hline Jenis Kelamin & 183 & 64 & 105 & 36 \\
\hline Berat Badan & 2 & 1 & 286 & 99 \\
\hline
\end{tabular}

Tabel 2. Kelengkapan data terkait dokter resep secara administratif

\begin{tabular}{ccccc}
\hline Data Terkait Dokter & \multicolumn{2}{c}{ Ada } & \multicolumn{2}{c}{ Tidak Ada } \\
\cline { 2 - 5 } & f & \% & f & \% \\
\hline Alamat & 282 & 99 & 4 & 1 \\
\hline Nama Dokter & 270 & 93 & 18 & 6 \\
\hline Nomor Telfon & 245 & 85 & 43 & 15 \\
\hline SIP & 207 & 72 & 81 & 28 \\
\hline Paraf & 136 & 47 & 152 & 53 \\
\hline
\end{tabular}


Tabel 3. Data kelengkapan resep terkait tanggal resep

\begin{tabular}{ccccc}
\hline Kelengkapan & \multicolumn{2}{c}{ Ada } & \multicolumn{2}{c}{ Tidak Ada } \\
\cline { 2 - 5 } Administratif & f & \% & f & \% \\
\hline Tanggal Resep & 275 & 98 & 7 & 2 \\
\hline
\end{tabular}

Tabel 4. Kelengkapan resep secara farmasetik

\begin{tabular}{ccccc}
\hline Kelengkapan & \multicolumn{2}{c}{ Ada } & \multicolumn{2}{c}{ Tidak Ada } \\
\cline { 2 - 5 } Farmasetik & f & \% & f & \% \\
\hline Stabilitas Obat & 287 & 99 & 287 & 99 \\
\hline Kekuatan Sediaan & 218 & 76 & 218 & 76 \\
\hline Bentuk Sediaan & 215 & 75 & 215 & 75 \\
\hline
\end{tabular}

Tabel 4. Tabel Kompatibilitas Obat

\begin{tabular}{ccccc}
\hline Kelengkapan & \multicolumn{2}{c}{ Ada } & \multicolumn{2}{c}{ Tidak Ada } \\
\cline { 2 - 5 } Farmasetik & $\mathbf{f}$ & $\boldsymbol{\%}$ & f & \% \\
\hline Kompatibilitas Obat & 27 & 100 & 0 & 0 \\
\hline
\end{tabular}

\section{DISKUSI}

Pada tabel 1 diketahui hasil analisis kelengkapan resep data terkait pasien secara administratif. Untuk ketidaklengkapan data terkait pasien yang mencakup sebanyak berat badan 99\% (286 lembar resep), jenis kelamin sebanyak 36\% (105 lembar resep), usia pasien sebanyak 28\% (82 lembar resep), nama pasien $1 \%$ (3 lembar resep).

Hasil ketidaklengkapan data terkait pasien ini sesuai dengan penelitian yang dilakukan Prawitasari (2009) yang mendapatkan hasil ketidaklengkapan penulisan data terkait pasien sebanyak 99\% berat badan pasien, $39 \%$ usia pasien, $36 \%$ jenis kelamin pasien, dan $2 \%$ nama pasien. Penelitian lain yang dilakukan oleh Daniel (2018) juga menampilkan hasil yang sesuai yaitu ketidaklengkapan penulisan data terkait pasien sebanyak 95\% berat badan pasien, $29 \%$ jenis kelamin pasien, $25 \%$ usia pasien, $1 \%$ nama pasien. Data terkait pasien dalam penulisan resep cukup penting, hal ini sangat diperlukan dalam proses pelayanan peresepan sebagai pembeda ketika ada nama pasien yang sama agar tidak terjadi kesalahan pemberian pada pasien. Seperti contohnya umur dan jenis kelamin pasien sangatlah penting dan harus dicantumkan didalam resep. Bentuk ketidaklengkapan data terkait pasien dalam resep yang diamati ini beragam, yaitu karena tidak dicantumkannya nama pasien, usia pasien, jenis kelamin, berat badan atau bahkan tidak dicantumkan keempatnya (Bilqis, 2015).

Pada tabel 2 diketahui hasil analisis kelengkapan resep data terkait dokter 
secara administratif. Selanjutnya hasil ketidaklengkapan penulisan data terkait dokter yang mencakup nama dokter sebanyak 6\% (18 lembar resep), SIP sebanyak 28\% (81 lembar resep), alamat sebanyak 1\% (4 lembar resep), nomor telfon sebanyak 15\% (43 lembar resep), paraf sebanyak 53\% (152 lembar resep).

Hasil ketidaklengkapan data terkait pasien ini sesuai dengan penelitian yang dilakukan Atmaniah (2018) yang mendapatkan hasil ketidaklengkapan penulisan data terkait dokter sebanyak nama dokter 44\% (167 lembar resep), SIP sebanyak 60\% (227 lembar resep), alamat sebanyak 0\% (0 lembar resep), nomor telfon sebanyak $0 \%$ (0 lembar resep), paraf sebanyak 86\% (327 lembar resep). Penelitian lain yang dilakukan oleh Daniel (2018) juga menampilkan hasil yang sesuai yaitu ketidaklengkapan penulisan data terkait dokter sebanyak $5 \%$ nama dokter, SIP 25\%, alamat 0\%, nomor telfon 9\%, paraf 45\%.. Menurut Cohen (2009), komunikasi yang buruk antara dokter dan apoteker dapat menyebabkan medication error. Tidak adanya nomor telfon dokter menyebabkan apoteker tidak bisa menghubungi dokter penulis resep ketika terjadi masalah pada fase prescribing maupun dispensing. (Cohen,2009)
Pada tabel 3 diketahui hasil analisis kelengkapan resep data terkait tanggal resep secara administratif. Hasil ketidaklengkapan penulisan data terkait tanggal resep sebanyak 2\% (7 lembar resep). Hasil ketidaklengkapan data terkait tanggal resep ini sesuai dengan penelitian yang dilakukan Atmaniah (2018) yang mendapatkan hasil ketidaklengkapan penulisan data terkait tanggal resep sebanyak 0\%. Penelitian lain yang dilakukan oleh Daniel (2018) juga menampilkan hasil yang sesuai yaitu ketidaklengkapan penulisan data terkait tanggal resep sebanyak 0\%. Tanggal penulisan resep harus dicantumkan untuk keamanan pasien dalam hal pengambilan obat. Karena apoteker dapat menentukan apakah resep tersebut masih bisa dilayani atau pasien disarankan kembali ke dokter yang bersangkutan (Atmaniah, 2018).

Pada penelitian selanjutnya resep dianalisan terhadap kelengkapan resep secara farmasetik. Pada tabel 4 diketahui hasil analisis kelengkapan resep secara farmasetik. Untuk ketidaklengkapan resep secara farmasetik terkait dengan bentuk sediaan sebanyak 25\% (75 lembar resep), dan untuk ketidaklengkapan resep secara farmasetik terkait dengan kekuatan sediaan sebanyak 24\% (70 lembar resep). Hasil ketidaklengkapan data terkait bentuk sediaan dan kekuatan sediaan ini 
sesuai dengan penelitian yang dilakukan Bilqis (2015) yang mendapatkan hasil ketidaklengkapan penulisan bentuk sediaan dan kekuatan sediaan sebanyak $23 \%$ bentuk sediaan, dan $33 \%$ kekuatan sediaan. Penelitian lain yang dilakukan oleh Daniel (2018) juga menampilkan hasil yang sesuai yaitu ketidaklengkapan penulisan terkait bentuk dan kekuatan sediaan sebanyak $30 \%$ bentuk sediaan, 27\% kekuatan sediaan. Menurut Joenes (2010), informasi mengenai bentuk dan kekuatan sediaan perlu dituliskan, terutama untuk obat-obatan yang memiliki beragam bentuk sediaan dan dosis. Tidak adanya informasi tersebut dapat menyebabkan kesalahan di fase dispensing (Joenes, 2010).

Pada tabel 4 diketahui hasil analisis kelengkapan resep secara farmasetik. Selanjutnya hasil ketidaklengkapan resep secara farmasetik terkait stabilitas obat. Pada penelitian kali ini stabilitas obat dianggap stabil semua untuk sediaan obat jadi karena untuk penyimpanan obat di Apotek k-24 Pos Penumben sesuai dengan suhu penyimpanan yang dianjurkan setiap obatnya, jadi untuk stabilitas obat hanya diperiksa untuk sediaan racikan saja yaitu sebanyak 27 resep. Pada data terkait stabilitas obat terdapat $1 \%$ yaitu satu resep racikan yang tidak stabil dalam penyimpanan, yaitu resep pulveres dengan kandungan natrium diklofenak yang merupakan tablet salut enterik. Penggerusan yang dilakukan dipastikan merusak salut enterik yang bertujuan agar obat relatif tidak larut pada asam lambung, tetapi larut dan hancur dalam lingkungan basa usus halus. Hasil penelitian ini sesuai dengan penelitian yang dilakukan oleh Daniel (2018) yang mendapatkan hasil data terkait stabilitas obat sebanyak 3\% yaitu dengan resep racikan yang mengandung Etaphylline yang merupakan tablet salut selaput. Penelitian lain yang dilakukan oleh Ebtarini (2010) juga menampilkan hasil yang sesuai yaitu mendapatkan hasil data terkait stabilitas obat sebanyak $1 \%$. Ebtarini (2010), dalam penelitiannya mengatakan bahwa sediaan racikan dipengaruhi oleh suhu, lama penyimpanan dan sifat fisika kimia kandungan obat didalamnya. Dirusaknya salut enterik natrium diklofenak dapat menyebabkan obat tersebut tidak stabil dalam bentuk pulveres (Ebtarini, 2010).

Pada tabel 5 diketahui hasil analisis kelengkapan resep secara farmasetik terkait kompatibilitas obat. Karena pada kompatibilitas obat itu terkait dengan ketercampuran obat jaid pada penelitian ini hanya dilakukan untuk resep racikan yang periksa kompatibilitas obatnya yaitu sebanyak 27 resep. Semua resep racikan 
$100 \%$ kompatibel (tercampur) karena dalam kegiatan peracikan di Apotek K-24 Pos Pengumben penggerusan dan pencampuran obat yaitu menggunakan blender jadi obat yang di racik pasti tergerus dan tercampur dengan sempurna. Hasil penelitian ini juga sesuai dengan penelitian yang dilakukan oleh Daniel (2018) yang mendapatkan hasil kompatibilitas obat yaitu $100 \%$ kompatibel. Penelitian lain yang dilakukan oleh Ebtarini (2010) juga menampilkan hasil yang sesuai yaitu 100\% kompatibel. Kompatibilitas merupakan suatu kondisi ketercampuran antara bahan obat dengan bahan obat lain atau dengan pelarut (Sharly, 2016).

\section{SIMPULAN}

Pada penelitian ini, masih banyak ditemukan ketidaklengkapan dalam penulisan resep menurut PERMENKES RI No.73 Tahun 2016 tentang standar pelayanan kefarmasian di apotek.

\section{DAFTAR PUSTAKA}

Atmaniah. 2018. Karya Tulis Ilmiah : Pengkajian Resep Secara Administratif pada Resep Pasien Rawat Jalan di RSU Kota Tangerang Selatan pada Bulan Februari 2018. Tangerang Selatan
Bilqis, Ulfa, S. 2015. Skripsi : Kajian Administrasi, Farmasetik dan Klinis Resep Pasien Rawat Jalan di RUMTIKAL DR. MITOHARDJO pada Bulan Januari 2015. Jakarta Cohen, M. (2009). Medication error $2^{\text {nd }}$ Edition. Washington DC :American Pharmaceutical Association Daniel, Hoedojo, C. 2018. Skripsi : Kajian Administrasi, Farmasetik dan Klinis Terhadap Resep Bagi Pasien Pediatri di Apotek " $X$ " Purwokerto. Yogyakarta.

Departemen Kesehatan Republik Indonesia Tahun 2009

Ebtarini, 2010. Skripsi: Tinjauan Aspek Farmasetis pada Resep Racikan di Lima Apotek di Kotamadya Pekalongan Periode Januari sampai Juni 2009. Pekalongan Hartayu, T.S., dan Widayati, A. Kajian Kelengkapan Resep Pediatri yang berpotensi menimbulkanMedication Error di Rumah Sakit dan 10 Apotek di Yogyakarta. Yogyakarta Joenoes, Z . 2009. ARS Prescribendi : Resep yang Rasional. Surabaya Katzung, Bertram G. 2009. Farmakologi Dasar dan Klinik Edisi Pertama.

Jakarta: Salemba Medika

Notoadmodjo, S. 2010. Metodologi Penelitian. Jakarta: Rieka Cipta 
Octavia, Hanna. 2011. Skripsi: Analisis Kelengkapan Peresepan di Apotek KPRI RSUD DR. SOETOMO Bulan Desember 2010. Surabaya

Peraturan Menteri Kesehatan Republik Indonesia No. 73 Tahun 2016

Peraturan Menteri Kesehatan Republik Indonesia No. 35 Tahun 2014

Peraturan Pemerintah Republik Indonesia No. 51 Tahun 2009

Prawitasari, Diah. 2009. Skripsi: Tinjauan Aspek Legalitas dan Kelengkapan Resep di 5 Apotek Kabupaten Klaten Tahun 2007. Surakarta

Sandy, 2010. Skripsi: Studi Kelengkapan Resep Obat Untuk Pasien Anak di Apotek Wilayah Kecamatan Kartasura Bulan Oktober sampai Desember 2008. Surakarta

Sharly, Dwijayanti. 2016. Jurnal : Profil Kompatibilitas Sediaan Intravena dengan Pelarut pada Pasien

Intensive Care Unit. Surabaya

Sugiyono. 2011. Metode Penelitian

Kualitatif Kuantitatif dan $R \& D$.

Jakarta: Alfabeta

Syamsuni, H.A. 2010. Ilmu Resep.

Jakarta.: Buku Kedokteran EGC

Sukmajati, Arum, M. 2009. Skripsi :

Pelaksanaan Standar Pelayanan

Kefarmasian di Apotek Berdasarkan KEPMENKES RI Nomor 1027/MENKES/SK/IX/2004 di Kota Yogyakarta. Yogyakarta

Wibowo, A. 2010. Skripsi: Analisis Kelengkapan Resep di Apotek Wilayah Lamongan Bulan Februari 2010. Surabaya

Wihartini, 2009. Membangun Budaya Keselamatan Pasien dalam Praktik Kedokteran Sehari-hari di Poliklinik umum Maranatha. Yogyakarta 